\title{
High-grade osteosarcoma of the mandible: a rare tumor successfully treated with surgery and image- guided volumetric modulated arc therapy
}

\author{
Irfan Ahmad, Chandi Prasad Bhatt, Irfan Bashir, Sandeep Rathour
}

Department of Radiation Oncology, Batra Hospital and Medical Research Centre, New Delhi, Delhi, India

Correspondence to Dr Irfan Ahmad, irfan.a@icloud.com

Accepted 8 July 2018
Check for updates

(c) BMJ Publishing Group Limited. No commercial re-use. See rights and permissions. Published by BMJ.

To cite: Ahmad I, Bhatt CP, Bashir I, et al. BMJ Case Rep Published Online First: [please include Day Month Year]. doi:10.1136/bcr-2018 226516

\section{DESCRIPTION}

A 69-year-old woman presented with complaints of tingling sensation over the right side of her lower lip for the last 5 months and a progressively increasing swelling over the right cheek for the last 2 months. On clinical examination, an ill-defined, non-tender mass with bony hard consistency was noted in the right body of mandible, which was fixed to underlying bone. She underwent a contrast-enhanced CT (face and neck), which revealed a mixed lytic-sclerotic lesion with poorly circumscribed margins situated in the body of the mandible on the right side along with a sunburst periosteal reaction (figure 1). A contrast-enhanced MRI (face and neck) further revealed bone marrow oedema adjacent to the lesion (figure 1). A biopsy from the lesion suggested a diagnosis of chondrosarcoma and a systemic staging evaluation was normal.

The case was discussed in a multidisciplinary tumour board (MDT) meeting and the patient underwent an en bloc right hemimandibulectomy with modified radical neck dissection along with a pectoralis major myocutaneous flap reconstruction. Histopathological evaluation of the surgical specimen revealed a chondroblastic osteosarcoma (grade 3) with a microscopically involved anterior bony margin and no involved lymph nodes (0/11 nodes positive). Immunohistochemical evaluation revealed positive labelling for vimentin, with a Ki-67 index of $30 \%-40 \%$ (figure 2). The final diagnosis of the patient was a chondroblastic osteosarcoma of the mandible American Joint Committee on Cancer stage IIA (pT1 pN0 cM0 G3). After an uneventful postoperative recovery, the case was reviewed in a MDT and due to the presence of positive surgical margin, she was advised adjuvant radiotherapy with image-guided volumetric modulated arc technique. She received $66 \mathrm{~Gy}$ in 33 fractions over $6 \frac{1}{2}$ weeks (figure 3 ). The patient tolerated treatment well and developed Radiation Therapy Oncology Group grade 2 skin toxicity. On follow-up evaluation at 2 weeks, her skin toxicity had resolved and a whole-body ${ }^{18}$ flourodeoxyglucose PET CT done 3 months later revealed no recurrence. At the time of last follow-up, she has been disease free for 6 months.

Osteosarcomas of the head and neck region $(\mathrm{OHN})$ comprise less than 2\%-10\% of all cases of osteosarcomas. ${ }^{12}$ They affect an older population and are associated with high lethality

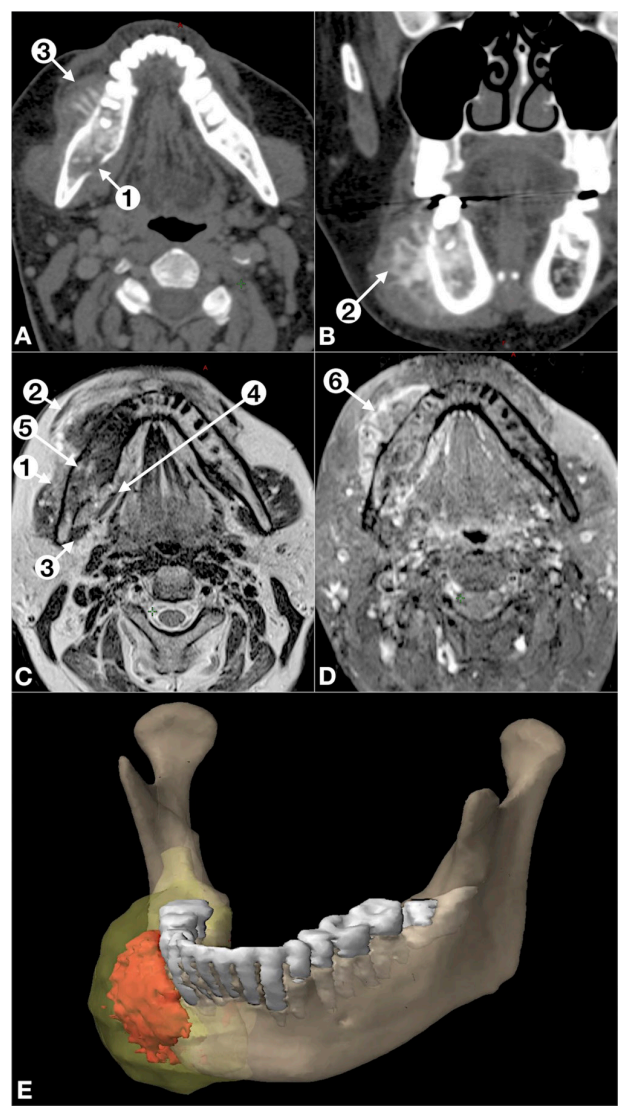

Figure $1 \quad(A, B)$ Contrast-enhanced CT slices in axial and coronal plane demonstrating a poorly circumscribed mixed lytic-sclerotic lesion in the body of the mandible on the right side, with cortical disruption (numbered arrow 1), periosteal reaction of sunburst type (numbered arrow 2) and accompanying heterogeneous soft-tissue mass (numbered arrow 3). (C, D) Axial T2 and T1 postcontrast sequence demonstrating the lesion abutting the right masseter muscle (numbered arrow 1) and causing alteration in the signal intensity of its fibres. The lesion is also abutting the buccinator (numbered arrow 2), medial pterygoid (numbered arrow 3) and mylohoid (numbered arrow 4) muscles. Bone marrow oedema is also present in the ipsilateral mandible adjacent to the lesion (numbered arrow 5). The lesion shows heterogeneous contrast enhancement (numbered arrow 6). (E) Three-dimensional model view of the patient's mandible and tumour topography created with a combination of manual highresolution delineation and semiautomatic Hounsfield Unit-based delineation. The mandible (translucent brown), soft-tissue component of the tumour (translucent yellow), osteoid formation (red) and lower dentition are shown. 


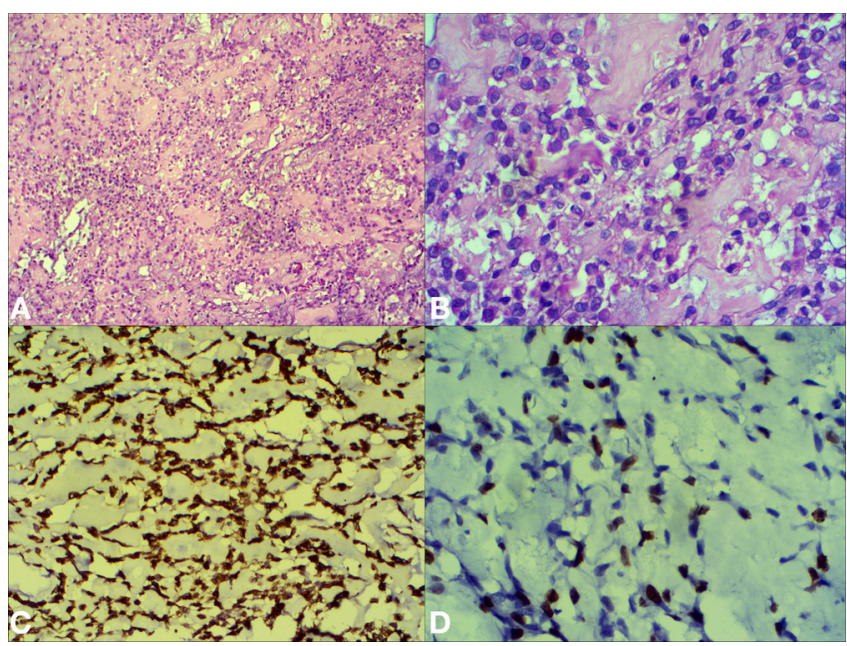

Figure 2 Microphotographs and immunohistochemical results. (A) Microphotograph showing sheets of polyhedral spindle cells with areas of admixed chondroblastic differentiation and lace-like eosinophilic amorphous osteoid with intermingled tumour cells $(H \& E, \times 100)$. (B) Microphotograph showing neoplastic polyhedral spindle cells of variable appearance with round to irregular nuclei with moderate to marked nuclear atypia $(H \& E, \times 400)$. (C) Immunohistochemical results showing immunopositivity for vimentin $(\times 400)$. (D) Immunohistochemical results showing moderate Ki-67 immunopositivity $(\times 400)$.

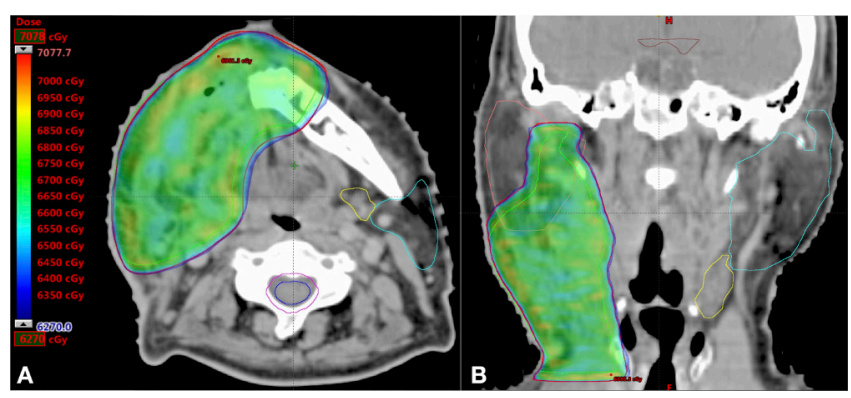

Figure 3 Image-guided volumetric modulated arc technique planning images. (A, B) Dose colour wash in axial and coronal planes with the lower dose limit set to $95 \%$ of $66 \mathrm{~Gy}$, demonstrating conformal dose deposition around the planning target volume (shown in red contour) and the clinical target volume (CTV) (green contour). Since the anterior bony margin was positive, note that the CTV extends generously into the remaining hemimandible. Also note the sparing of the right parotid (pink contour), left parotid (blue contour) and left submandibular gland (yellow contour).

owing to local disease that is difficult to control. ${ }^{2}$ In contrast, extremity osteosarcoma affects a younger population and demonstrates a higher incidence of distant metastases. The distinct clinical behaviour of OHN mandates an emphasis on achieving negative surgical margins, which is a challenge, therefore necessitating the incorporation of localised radiotherapy. ${ }^{23}$ In patients with close or positive surgical margins, radiotherapy improves local control, overall survival and disease-free survival. ${ }^{3}$ Since osteosarcomas are considered radioresistant, at least 60 Gy should be delivered, which leads to a complication rate of $40 \%$ at 5 years. ${ }^{3}$ However, the reported complication rate is with the use of older radiotherapy techniques, and as demonstrated in this case, modern techniques provide the opportunity to reduce their incidence. In conclusion, $\mathrm{OHN}$ is a distinct subtype of osteosarcoma that should be managed with radical surgical excision with consideration for adjuvant radiotherapy for close/positive surgical margins.

\section{Learning points}

- A bony hard swelling centred over the mandible should be investigated keeping in mind the possibility of diagnosing a malignant bone tumour.

- Surgical excision is the standard of care for treating mandibular osteosarcomas and adjuvant radiotherapy should be considered when surgical margins are involved.

- Modern radiotherapy delivery techniques are necessary for ensuring an optimal outcome with low treatment-related complications.

Contributors IA is the treating junior consultant (Radiation Oncology), author of the paper, responsible for drafting the manuscript and revising it. He is the guarantor. CPB is the physicist, responsible for generating the radiation treatment plan, performing quality assurance of delivered plan and also participated in article editing. IB is the supervising treating consultant (Radiation Oncology) and participated in article formulation, editing and oversight. SR is the technologist, responsible for creating the treatment set-up and ensuring reproducible positioning during the course of treatment. He also participated in article formulation and editing.

Funding The authors have not declared a specific grant for this research from any funding agency in the public, commercial or not-for-profit sectors.

Competing interests None declared.

Patient consent Obtained.

Provenance and peer review Not commissioned; externally peer reviewed.

\section{REFERENCES}

1 Jasnau S, Meyer U, Potratz J, et al. Craniofacial osteosarcoma Experience of the cooperative German-Austrian-Swiss osteosarcoma study group. Oral Oncol 2008;44:286-94.

2 DeLaney TF, Park L, Goldberg SI, et al. Radiotherapy for local control of osteosarcoma. Int J Radiat Oncol Biol Phys 2005;61:492-8.

3 Guadagnolo BA, Zagars GK, Raymond AK, et al. Osteosarcoma of the jaw/craniofacial region. Cancer 2009;115:3262-70. 
Copyright 2018 BMJ Publishing Group. All rights reserved. For permission to reuse any of this content visit http://group.bmj.com/group/rights-licensing/permissions.

BMJ Case Report Fellows may re-use this article for personal use and teaching without any further permission.

Become a Fellow of BMJ Case Reports today and you can:

- Submit as many cases as you like

- Enjoy fast sympathetic peer review and rapid publication of accepted articles

Access all the published articles

Re-use any of the published material for personal use and teaching without further permission

For information on Institutional Fellowships contact consortiasales@bmjgroup.com

Visit casereports.bmj.com for more articles like this and to become a Fellow 